\title{
Stylistic Awareness to Analyze and Comprehend Authentic Discourse in Language Classrooms
}

\author{
Rabih Joseph Nabhan \\ Holy Spirit University of Kaslik (USEK), Kaslik, Lebanon \\ Email: rabihnabhan@usek.edu.lb
}

How to cite this paper: Nabhan, R. J. (2017). Stylistic Awareness to Analyze and Comprehend Authentic Discourse in Language Classrooms. Open Journal of Modern Linguistics, 7, 185-195.

https://doi.org/10.4236/ojml.2017.73014

Received: May 2, 2017

Accepted: June 9, 2017

Published: June 12, 2017

Copyright $\odot 2017$ by author and Scientific Research Publishing Inc. This work is licensed under the Creative Commons Attribution International License (CC BY 4.0).

http://creativecommons.org/licenses/by/4.0/

\begin{abstract}
Stylistic awareness of a text-the knowledge of syntactic, semantic, and/or pragmatic features-leads to an overall understanding of a discourse. The study will focus on the stylistics of news genre as authentic material in classrooms. The aim of this article is to draw a comparison between the language features used in online news and those used in the printed newspapers to underscore the linguistic characteristics of such media. The data to analyze will be collected from two European news media. The electronic tool will be the BBC online news http://www.bbc.co.uk/news/, while the printed one will be International Herald Tribune. The purpose of this study is to highlight the linguistic variations, if they exist, between the two media. The language will be studied in terms of syntax, semantics, and pragmatics, showing how these linguistic subfields can affect the language and determine the level of complication in understanding meaning. For discourse analysis, the same theme and topic will be selected. Examples and samples from both media will be posted to display the differences of language use. The comparison will be organized and divided into three subtitles: Syntactic Differences, Pragmatic Differences, and Semantic Differences. The paper will also focus on the effect of hyperlinks on the language and how the unlimited amount of information compressed in the virtual media make the online news unique. In addition, the limitations and weaknesses of both media will be addressed to take the research a step forward in order to make teachers aware of the flaws while using these genuine objects in language classrooms.
\end{abstract}

\section{Keywords}

Language Features, Awareness, Differences, Online News, Print, Authentic Materials, Syntax, Pragmatics, Semantics, Hyperlinks, Limitations, Discourse Analysis, Language Classroom 


\section{Introduction}

Jakobson (1960) states that there is a substantial relationship between linguistics and literary studies and a competence of language traits can enrich the understanding of different discourse. Hence, linguistic awareness is significant in language classrooms, especially when utilizing authentic material that transports the students from the classroom environment to the real world outside. When teachers are aware of the variations of language features in genuine discourse, they can reflect this knowledge in their classes and consequently instruct their learners of such variations.

Widdowson (1992) states that it is imperative to whet the students' perception of how language is exploited to express different aspects of reality. When learners understand the use and influence of certain language features on different discourse, they will be able to analytically comprehend an authentic text which will prepare them to texts and reading dissertations in their future life. Hoey (1989) mentions that every discourse has its unique linguistic organization and he proposes that "a useful interpretation of a literary work can be reached by an analysis of the text's organization as discourse" (p. 121).

Print and online discourses have been extensively implemented as authentic material in language classrooms. Educators use print and online magazines, journals and newspapers to prepare their learners to a wider variety of discourse they might encounter later in life. Such authentic materials are common for reading at the comprehension level for entertainment rather than for analysis and evaluation. However, for a better recognition and a higher text conception, a linguistic knowledge is essential. This linguistic knowledge is intended for teachers as well as for learners. Teachers must be aware of the linguistic differences which must also be taught to their students so that they become independent knowledgeable readers. Therefore, the main purpose of the analyses and results in this paper is to help educators and learners acknowledge variances between the two similar teaching and learning tools. The main intention is wider interaction with the outside world via the correct use of authentic material, and thus preparing learners for the post education phase of their life.

\section{Literature Review}

Two types of text genres are the main focus of our study: the print news discourse verses the online news discourse. The notion of discourse fuses these two news media, yet linguistically speaking, the two types of discourse are distinct since each rises from a different context. Jackson and Moulinier (2002), Aitchison and Lewis (2003), and Montgomery (2007) confirm that language or discourse is a contextualized activity and that any instance of discourse or language in use bears the trace of its context.

Print news discourse, according to Treloar (2001), are eminently portable and can be transported from one place to another and read any time the user wishes. Reading a print discourse can be manipulated according to the reader's desires. Articles can be highlighted and underlined with comments and notes for later 
reference. In addition, print discourse has the significant benefit of familiarity. School students, Treloar (2001) adds, do not need to go through any training to be familiarized with published discourses as it is evident when one watches someone interact with print.

Online news discourse has its own distinctiveness. Lewis (2003) states that this new genre of news is characterized by a single coding mechanism. It integrates writing, sound, image, and video, a single textual space accumulating an unlimited amount of diverse information, new different patterns of interaction, and different connotations since it is a different medium. Structurally, online news is distinguished by the hypertext which, according to Lewis (2003) and Bexten (2006), creates content layers creating several levels of detail.

A single document in a hypertext system can be very similar to a piece traditional text. However, the structure of online news with the function of hypertext provides a richly integrated web material. Shapiro (1998) mentions that "the important difference between hypertext-based information and traditional text-based materials is the network of links connecting nodes" (pp. 3-4). While traditional discourse form a linear reading sequence, online texts, through hypertexts, split up and then recombines. Whatever the reader does to "re-linearise the hypertext", to use Bexten term (2006: p. 117), the text structurally remains a network. Online discourse, therefore, is presented in the form of network-like texts: a single information unit can occur at various places in different reading sequences.

\section{Methodology}

From the perspective of linguistics, as is confirmed in the literature review, traditional and online discourses are distinct. However, similarities still exist. Lewis (2003) and Landow (2006) assert that with the appearance of online news, common trends can be discerned, while stylistic conventions are emerging.

The linguistic differences between the traditional and online discourses represented by International Herald Tribune and BBC online news will be analyzed in this paper. The same topic and theme articles of May $9^{\text {th }}, 2011$ will be utilized from the two genres. The stylistic analysis will tackle the variations on the syntactic, semantic, and pragmatic levels. The three levels of analysis are so interwoven that none of them can be ignored when studying discourse. In fact, pragmatics is a link between syntax and semantics (Van Valin Jr., 2008). Syntax brings isolated words together which results in working on words in context i.e. pragmatics. In addition, syntax is a gateway to meaning and it "cannot, and should not, totally exclude considerations of meaning" (Brown \& Miller, 1991: p. 4) and "pragmatics is about the interaction of semantic knowledge with our knowledge of the world" (Griffiths, 2006: p. 1). For illustration, samples from both media will be utilized and the analysis will be carried out on the three levels of syntax, semantics, and pragmatics because, as mentioned earlier, none of the three levels can ignored when it comes to discourse analysis. Examples from both media will be exploited to make the differences clear and up to the level of 
understanding.

\section{Analysis}

On the syntactic level, most paragraphs in print as well as online start with subject and auxiliary be, with some instances of other verbs (Appendices A and B for illustration). This gives both genres the descriptive quality of tackling news.

Paragraphs in print are often of more than one sentence. Details continue from one paragraph to the other. In online news, paragraphs often consist of a single idea in a single sentence. In both print and online discourses words form sentences and sentences form paragraphs. However, in print the result is a whole unified text like an essay, while in online the result is a segmented text, specifically with the presence of hypertext (Appendices A and B for illustration).

Since pragmatics is the contextualized study of semantics (Griffiths, 2006), these two levels will be analyzed simultaneously. It is evident in both news genres the multiple use of phrasal verbs (Table 1), which denotes the use of "more oral features to appeal to a wider reading audience" (Biber, 2003: p. 170). Hence, media discourse is a formal language that adheres to the informal verbal communication.

The concept of passivity and participatory, pointed out by Landow (2006) and Shapiro (1998), is realized through not only the employment of hyperlinks but also the pragmatic structure of the sentences. Here the theory of speech acts can be utilized. Griffiths (2006) mentions that "speech acts can be done in writing, not only in speaking" (p. 148). Let's consider the first sentence from each sample at hand:

- Manchester United is once again the English Premier League champion in all but name. (International Herald Tribune).

- It is almost impossible to pick out individuals in analysing why Manchester United recorded a deserved victory over Chelsea which all but seals a record 19th top-flight league title (BBC).

The first sample seems fixed and straight to the point. The reader is just receptive and moves with the words without the feeling of involvement. In the second sample, the utterance "It is almost impossible to pick out individuals" is an indirect speech act engaging the reader in reflecting about the matter being discussed. As a result, language of online discourse creates active readers.

Text bifurcation, the splitting up of discourse (Bexten, 2006), exists in both genres, however, in two different techniques. In newspaper, most articles of page one end with one word dissection and a page number at which the dissected

Table 1. The multiple use of phrasal verbs in both genres.

\begin{tabular}{cccc}
\hline \multicolumn{2}{c}{ Print (International Herald Tribune) } & \multicolumn{2}{c}{ Online (BBC Online News) } \\
\hline Sped away & Poked over & Pick out & Floating around \\
Was over & Coming off & Recorded over & Close down \\
Went further & Find out & Swept away & Pick up \\
Send off & Take back & Put ahead & Help out \\
Put out & Went off & Put through & \\
\hline
\end{tabular}


word recombines to continue the piece (Appendix C). Some articles end with a full word and a page number. In online, text divergence starts from the first page through the use of hyperlink, a hypertext which exists in the entire report (Appendix B). Synonyms are used to connect texts. The following two samples can illustrate this notion.

Sample 1:

- The overall team display at Old Trafford swept away any doubts that United warrant a 12 th Premier League crown with their defence solid, the midfield of Michael Carrick and Ryan Giggs working in almost perfect tandem and the frontline of Wayne Rooney and Javier Hernandez a force up front.

Clicking the hyperlink (underlined), the text recombines with the following piece:

- Manchester United moved to within a point of a record 19th title after a deserved win against closest rivals Chelsea at an exultant Old Trafford.

"Manchester United" refers to "team".

Sample 2:

- It also provided some interesting clues about a developing midfield with United's Champions League final against Barcelona looming on the horizon.

Clicking the hyperlink (underlined), the text recombines with the following piece:

- FC Barcelona and Manchester United FC will visit Wembley on Saturday 28

May out to write another chapter in their rich history - the past suggests there will be little to choose between them.

"FC Barcelona and Manchester United FC" refers to "United's Champions League final against Barcelona”.

It is well noting that in print the text is incomprehensible without its two parts, whereas in hypertext the hyperlink connects to a supplementary unit.

\section{Hypertext}

Hypertexts are abundant in online news discourse. Learners must make use of them because they take them deeper to wider range of information. Educators themselves should know the importance of hypertexts, and thus transfer their knowledge to their students. In fact, "Hypertext is non-sequential text which is organised to allow readers/users access to non-linear information" (Son, 1998: p. 113). Hypertexts are special (Bexten, 2006) and they offer unique features (Chakrabarti, 2003). Through hypertext, the web offers vast amount of information in comparison with print. Information is at the reader's finger tips just by clicking the hyperlink. Hypertext is encyclopedic as the reader can obtain the information he wants rather than what is printed and self-contained. In addition, it is flexible as it can facilitate words, pictures, audio, video and graphics.

Shapiro (1998) reports that structures such as those of hypertexts can augment learning. Hypertexts would create more active processing and would lead to an increased capacity for education as they "add significant amounts of useful information" (Chakrabarti, 2003: p. 12). They have great potential in language 
learning and can enrich reading tasks by providing learners with various types of content data. Learners can manage to work independently and explore information on the basis of their personal preferences and needs.

\section{Limitations}

Print and online news discourses have similarities as well as differences. Both can be used as authentic material in classrooms. However, teachers must be aware of some limitations. Print discourse might be dull for a classroom environment since it cannot capture the sound and movement required by an audience raised on the audio and video of television and the Internet. In other words, students might feel that the learning process is still done in their boring books. Here it is the teacher's role to select appealing reading tasks. In addition, the reading selection must cope with the students' level; otherwise, it will act as a dispiriting factor leading to an unsatisfactory performance.

With the indispensable hypertext feature, online media present students with masses of information that their brain might burst with cognitive overload. In addition, following different paths while reading may result in different and sometimes unfavorable learning consequences. Here the teacher's role is to direct the students to which links to follow and which to ignore.

\section{Conclusion}

Despite the limitations, print and online media can function as fine elements for authentic learning. Teachers must be aware of the linguistic similarities and differences between these two genres and consequently reflect their knowledge to their students. Same as clarifying the resemblance between narrative and descriptive texts, teachers can highlight the resemblance between the two media discourses. It should be an ordinary teaching process but which can take the learners beyond the traditional learning environment. Decoding the syntax, semantics, and pragmatics of both genres results in less text complications and the learning process will raise one step upward. The teacher should start the learning process by utilizing examples from both discourses. These examples can be jotted down in tables on the board and discussed and analyzed with the learners. The analysis should be on the level of syntax, semantics, and pragmatics. Consequently, the learners will be aware of the similarities and differences. In the next teaching process, the students themselves can draw their own tables, explain the samples, and comment on each other's samples. These two stages of the learning process will prepare the students to healthy discourse reading of the two genres, which will become naturally acceptable and understood in their future readings.

\section{References}

Aitchison, J., \& Lewis, D. M. (2003). Introduction. In J. Aitchison, \& D. Lewis (Eds.), New Media Language (pp. 1-3). London and New York: Routledge.

Bexten, B. (2006). Hypertext and Plurilinearity: Challenging an Old-Fashioned Discourse 
Model. Schedae, 14, 117-122.

Biber, D. (2003). Compressed Noun-Phrase Structures in Newspaper Discourse: The Competing Demands of Popularization vs. Economy. In J. Aitchison, \& D. Lewis (Eds.), New media Language (pp. 169-181). London and New York: Routledge.

Brown, K., \& Miller, J. (1991). Syntax: A Linguistic Introduction to Sentence Structure (2nd Edition). London and New York: Routledge.

Chakrabarti, S. (2003). Mining the Web: Discovering Knowledge from Hypertext Data. USA: Morgan Kaufmann Publishers.

Griffiths, P. (2006). An Introduction to English Semantics and Pragmatics. Edinburgh: Edinburgh University Press Ltd.

Hoey, M. (1989). Discourse-Centred Stylistics: A Way Forward? In R. Carter, \& P. Simpson (Eds.), Language, Discourse and Literature: An Introductory Reader in Discourse Stylistics (pp. 121-136). London and New York: Routledge.

Jackson, P., \& Moulinier, I. (2002). Natural Language Processing for Online Applications: Textretrieval, Extraction, and Categorization. Amsterdam/Philadelphia: John Benjamins Publishing Company. https://doi.org/10.1075/nlp.5(1st)

Jakobson, R. (1960). Linguistics and Poetics. In T. Sebeok (Ed.), Style in Language (pp. 350-377). Cambridge: Massachusetts Institute of Technology Press.

Landow, G. P. (2006). Hypertext 3.0: Critical Theory and New Media in an Era of Globalization. USA: The Johns Hopkins University Press.

Lewis D. M. (2003). Online News: A New Genre? In J. Aitchison, \& D. Lewis (Eds.), New Media Language (pp. 95-104). London and New York: Routledge.

Montgomery, M. (2007). The Discourse of Broadcast News: A Linguistic Approach. New York: Routledge.

Shapiro, A. M. (1998). Promoting Active Learning: The Role of System Structure in Learning from Hypertext. Human-Computer Interaction, 13, 1-35. https://doi.org/10.1207/s15327051hci1301_1

Son, J.-B. (1998). Understanding Hypertext: A Discussion for TEFL. English Teaching, 53, 113-124.

Treloar, A. (2001). Hypermedia Online Publishing: The Transformation of the Scholarly Journal. http://andrew.treloar.net/research/theses/phd/thesis-69.shtml

Van Valin Jr., R. D. (2008). Editor's Introduction. In R. D. Van Valin Jr. (Ed.), Investigations of the Syantx-Semantics-Pragmatics Interface (pp. xv-xxiv). Amsterdam/Philadelphia: John Benjamins Publishing Company.

Widdowson, H. G. (1992). Practical Stylistics. Oxford: Oxford University Press. 


\section{Appendix A}

Print Media Discourse

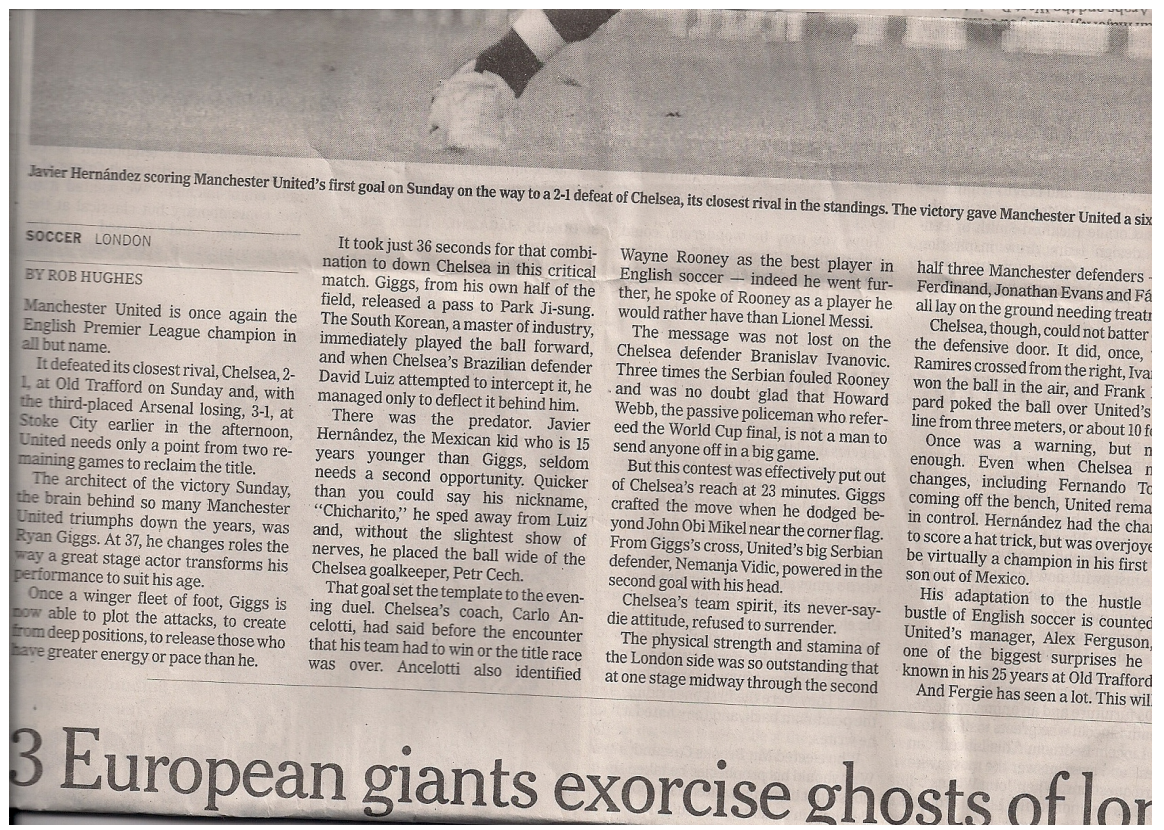

\section{Appendix B}

\section{Online Media Discourse}

Park peerless in United's decisive victory

Comments

236

- $\quad$ Share

- Facebook

- $\quad$ Twitter

Post categories: Football, football tactics

Alistair Magowan-BBC Sport | 00:05 UK time, Monday, 9 May 2011

It is almost impossible to pick out individuals in analysing why Manchester United recorded a deserved victory over Chelsea which all but seals a record 19th top-flight league title.

The overall team display at Old Trafford swept away any doubts that United warrant a 12th Premier League crown with their defence solid, the midfield of Michael Carrick and Ryan Giggs working in almost perfect tandem and the frontline of Wayne Rooney and Javier Hernandez a force up front.

Park Ji-sung's display was chief among the highlights too, particularly the South Korean's work-rate and cleverness which helped to thwart Chelsea's three-man midfield.

The 30-year-old is often preferred on the left of midfield in United's big games and although his defensive qualities put him ahead of Nani in the pecking order, he also offers a different slant to their attack.

This was evident right from the beginning of the game when Giggs expertly found Park in an inside-left position, before he put Hernandez through for his 
37-second opener which set the tone for a pulsating first half.

That key pass to Park is highlighted below, and the areas in which his teammates found him was markedly different to Antonio Valencia on the right.
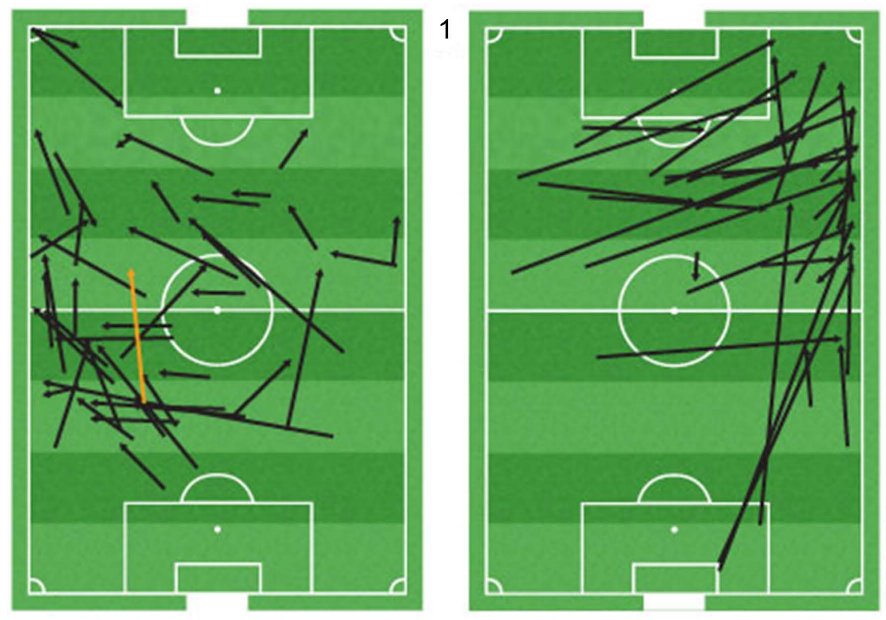

2

1. Passes to Park vs Chelsea 8 May 2011

2. Passes to Valencia vs Chelsea 8 May 2011

Floating around in a space between the defence and midfield where Chelsea right-back Branislav Ivanovic did not want to go, Park proved a menace.

It also provided some interesting clues about a developing midfield with United's Champions League final against Barcelona looming on the horizon.

"Firstly, Park set the tempo of the United team right from the start" says former Arsenal full-back and Match of the Day 2 pundit Lee Dixon. "They obviously had been primed to start quickly but they took Chelsea by surprise and I thought he was the main catalyst for that.

"His work-rate is a given and what we come to expect from him, but I thought his intelligence of when to close down when Chelsea had the ball, and his selection of space at the right time was brilliant.

"In attack he also occupies narrower positions but that makes the full-back think because he can go wide as well. He picks the ball up in areas that full-backs don't necessarily like to go in and mark.

"We tend to like staying in our area not too far away from our centre-back, and we feel uncomfortable when we go into that inside-left area unless we have really good cover. It's something that puts you in two minds: do I go in and mark him or do I stay where I am?

"The safe thing to do is stay where you are but because Park is so good on the ball like we saw for the goal, he is a dangerous person to leave alone. I thought he did a brilliant job and he tore Ivanovic to pieces at times."

You could argue that United selected a five-man midfield again, with Rooney dropping in to help out Giggs, Carrick, Park and Antonio Valencia. But where the formation failed last week against Arsenal, this time they were fluid in attack and solid in defence.

The key thing here is that although it might appear that Rooney was the only one playing in the space between Chelsea's defence and midfield the truth was that there were actually three of them: Rooney, Park and Giggs. 
And for someone like Chelsea's defensive midfielder John Mikel Obi that proved a nightmare.

Giggs may tend to carry the ball into that area rather receiving it there, but he was sorely missing from United's midfield at the Emirates last Sunday and based on recent European performances he is proving a perfect foil alongside Carrick.

When Carrick plays with Anderson or Paul Scholes, the central midfield pair line up more side-by-side, whereas with Giggs in the side Carrick plays a lot deeper, allowing the Welshman to probe in front of him.

That gives Giggs the chance to collect the ball in midfield and run at defenders, which commits them to a challenge. When this happens it can also leave gaps for Rooney and Hernandez.

Although Park moving infield might leave United narrow on the left side in attack, usually they have Patrice Evra who can overlap from full-back and fill the space that Park vacates.

When they are defending, Park is smart enough and fit enough to track back and decide whether to remain wide to help John O'Shea, as he did on Sunday, or come infield to assist.

That also goes for Valencia who tends to hug the touchline more on the right but was willing to shadow Chelsea full-back Ashley Cole.

Without that outlet on the left Chelsea were very narrow, which suited Sir Alex Ferguson's side.

"This week United got the balance right in midfield and got help in the right areas," Dixon adds. "Both Valencia and Park went back which sometimes freed one of the defenders to actually step into midfield from a defensive position.

"Valencia will run all day, there were loads of times when he was at rightback, and the amount of times Cole got in behind United's defence were few and far between so it shows he was doing his job.

"Chelsea's wider players Florent Malouda and Salomon Kalou tried to hunt for the ball, but they didn't stay that wide that often.

"Chelsea had lots of players who were very quiet and they just got hit by Manchester United who were in an attacking frame of mind. It surprised them and I think they thought that United would sit back and hit them on the break, therefore almost waiting for a draw. In fact, they did the opposite."

It may be stretching it to say that United will have learned useful lessons before they take on Barcelona at Wembley on 28 May, as the Catalans will offer a completely different conundrum to Chelsea.

Yet in the midfield where United's problems seemed to have stemmed from this season, they now appear to have made progress at exactly the right time.

And more importantly, if they begin the Champions League final at the same tempo they may just be able to catch out their opponents again. 
Appendix C

len's death offers tunity to unnerve and engage them ion they have so far

ah Omar," one of sama's top advisers lammad Omar, the jiritual leader, who operates from Pakistan, "you've got to wonder whether the next set of helicopters is coming for you."

The mystery now is whether the removal of Bin Laden as the central, mesmerizing figure in the battle between fundamentalists and the West is truly a tipping point, as the White House is betting, or whether it will prove more consequential to the debate in the United States about the pace of troop withTALIBAN, PAGE 5

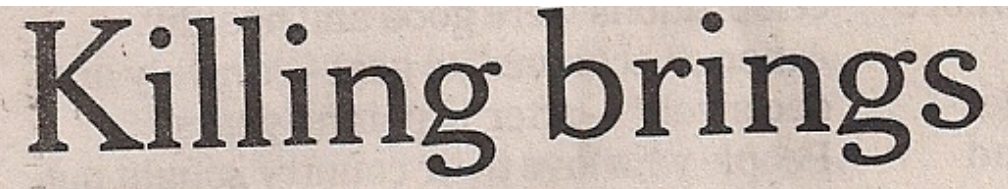

TALIBAN, FROM PAGE 1

voted

drawals from Afghanistan, set to begin

a local

this summer.

gone.

That may depend on a series of events

Mos that have yet to unfold: Whether $\mathrm{Al}$

surge Qaeda strikes back for the killing of its Pakis1 leader, whether the U.S. military force in Afghanistan remains at its current gence strength and whether Afghanistan's own military proves more capable than it has been so far in taking the lead in contested areas of the country.

Servir havel

Pak humil Bin L All last week, Mr. Obama and his aides main 
Submit or recommend next manuscript to SCIRP and we will provide best service for you:

Accepting pre-submission inquiries through Email, Facebook, LinkedIn, Twitter, etc. A wide selection of journals (inclusive of 9 subjects, more than 200 journals)

Providing 24-hour high-quality service

User-friendly online submission system

Fair and swift peer-review system

Efficient typesetting and proofreading procedure

Display of the result of downloads and visits, as well as the number of cited articles Maximum dissemination of your research work

Submit your manuscript at: http://papersubmission.scirp.org/

Or contact ojml@scirp.org 